\title{
Monitoring of Yersinia enterocolitica strains from free-living animals using different methods
}

\author{
K. Syczyło1, A. Platt-Samoraj ${ }^{1}$, A. Bancerz-Kisiel ${ }^{1}$, A. Szczerba-Turek¹, \\ K. Lipczyńska', A. Jabłoński², Z. Procajło', W. Szweda ${ }^{1}$ \\ ${ }^{1}$ Department of Epizootiology, Faculty of Veterinary Medicine, University of Warmia and Mazury, \\ Oczapowskiego 13, 10-718 Olsztyn, Poland \\ 2 The National Veterinary Research Institute, Al. Partyzantów 57, 24-100 Puławy, Poland
}

\begin{abstract}
The aim of the study was to monitor $Y$. enterocolitica strains from free-living animals captured during 2011-2014 hunting seasons in Poland using warm (ITC) and cold (PSB) enrichment and molecular examination. Over 1600 samples have been cultured. After ITC/PSB enrichment 237 strains presenting features characteristic for $Y$. enterocolitica were isolated. Molecular examination using multiplex PCR revealed 140 isolates from PSB and 78 from ITC. The concentration of pathogenic Yersinia in asymptomatic carriers is low and the PCR detection should be preceded by bacteriological examination.
\end{abstract}

Key words: Yersinia enterocolitica, bacteriological examination, multiplex PCR, free-living animals

\section{Introduction}

Yersinia (Y.) enterocolitica is an important foodborne pathogen belonging to the Enterobacteriaceae family. It is known as a cause of gastrointestinal disorders with symptoms depending on $Y$. enterocolitica bioserotype and the age of the host (Zadernowska et al. 2014). Clinical signs are ranging from acute enteritis with high fever to occasionally diarrhea, sometimes with blood (Hussein et al. 2001). The infection in animals is usually asymptomatic or accompanied by short-time diarrhea, but in humans it might be fatal in most severe cases (Shayegani et al. 1986). Y. enterocolitica is a Gram-negative bacterium with ability to multiply and survive in low temperature (Hussein et al. 2001). For this reason two types of culture are needed for proper and detailed isolation of $Y$. enterocolitica. Culturing is labour and time-consuming, so one of the most reliable and specific methods for pathogenicity verification in Yersinia look-like colonies seems to be molecular examinations as PCR (polymerase chain reaction) (Lambertz et al. 2007). PCR is based on detection of specific virulence markers. The most popular markers used for $Y$. enterocolitica are ail, yst $A$ and $y s t B$, genes encoding proteins responsible for adhesion and invasion to the intestinal cells, and production of the YstA and YstB enterotoxins, respectively (Bancerz-Kisiel et al. 2014). 
Table 1. Results of bacteriological and molecular examinations of samples from various wild animal species using ITC and PSB culture methods.

\begin{tabular}{|c|c|c|c|c|c|c|c|c|c|}
\hline \multirow{3}{*}{ Source } & \multirow{3}{*}{ No. of animal } & \multicolumn{4}{|c|}{ ITC } & \multicolumn{4}{|c|}{ PSB } \\
\hline & & \multicolumn{2}{|c|}{$\begin{array}{l}\text { bacteriological } \\
\text { examination }\end{array}$} & \multicolumn{2}{|c|}{$\begin{array}{c}\text { molecular } \\
\text { examination }\end{array}$} & \multicolumn{2}{|c|}{$\begin{array}{l}\text { bacteriological } \\
\text { examination }\end{array}$} & \multicolumn{2}{|c|}{$\begin{array}{c}\text { molecular } \\
\text { examination }\end{array}$} \\
\hline & & positive & $\%$ & positive & $\%$ & positive & $\%$ & positive & $\%$ \\
\hline Wild boars & 434 & 141 & 32.5 & 49 & 11.3 & 176 & 40.6 & 84 & 19.4 \\
\hline Red deer & 291 & 78 & 26.8 & 25 & 8.6 & 103 & 35.4 & 45 & 15.5 \\
\hline Roe deer & 87 & 15 & 17.2 & 2 & 2.3 & 17 & 19.5 & 9 & 10.3 \\
\hline Fallow deer & 16 & 3 & 18.8 & 2 & 12.5 & 5 & 31.3 & 2 & 12.5 \\
\hline Total & 828 & 237 & 28.6 & 78 & 9.42 & 301 & 36.4 & 140 & 16.9 \\
\hline
\end{tabular}

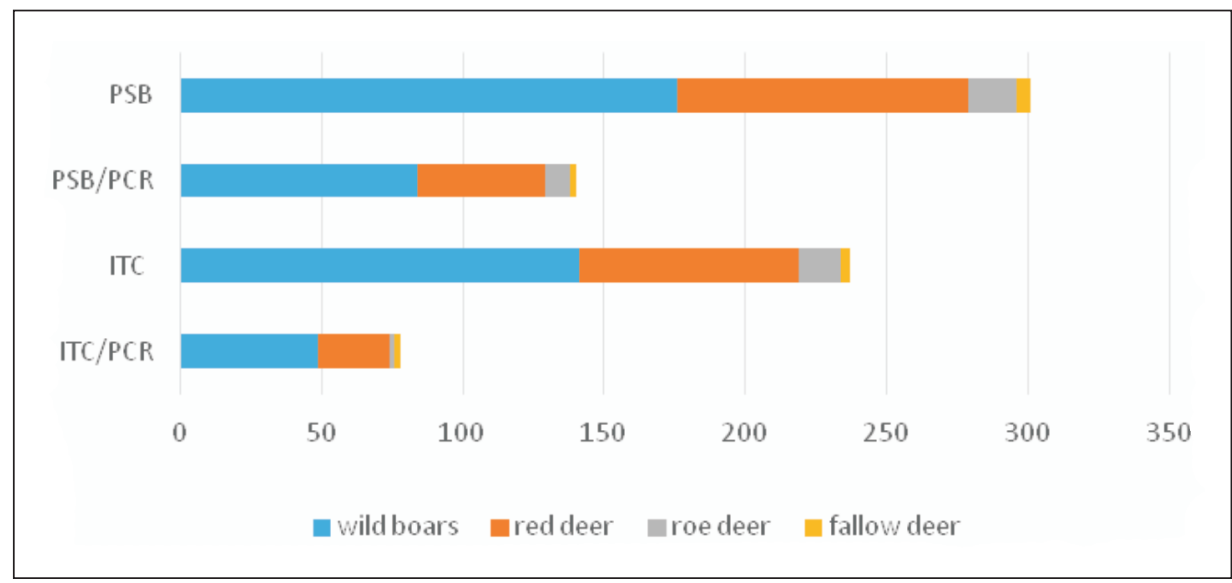

Fig. 1. The number of animals positive in each examination method.

Pigs are known as a main reservoir of $Y$. enterocolitica strains pathogenic for humans, and raw or undercooked pork as a primary source of infection for humans. Although other food products, as milk or tofu, have been implicated in outbreaks (Hanifian and Khani 2012). Pathogenic strains were also found in feces and carcasses of wild animals (Bancerz-Kisiel et al. 2014). Because of an increasing significance of wild game as a food and disability to check the health status of each hunted animal it is necessary to control dispersion of pathogenic $Y$. enterocolitica strains in the wildlife.

The purpose of the study was to monitor $Y$. enterocolitica strains from free-living animals captured during 2011-2014 hunting seasons in Poland using warm (ITC) and cold (PSB) enrichment in conjunction with multiplex PCR.

\section{Materials and Methods}

The material for the study consisted of 1656 rectal swabs from 828 wild animals - 434 wild boars (Sus scrofa), 291 red deer (Cervus elaphus), 87 roe deer (Capreolus capreolus) and 16 fallow deer (Dama dama). Samples were taken from free-living animals hunted mainly in North-Eastern Poland between 2011-2014. Two samples were taken from each animal and held on transporting medium before delivery to the laboratory. Swabs were then cultured simultaneously on ITC medium (irgasan ${ }^{\mathrm{TM}}$, ticarcillin, and potassium chlorate; warm enrichment) and PSB medium (pepton, sorbitol, and bile salt; cold enrichment). The ITC culture was incubated at $25^{\circ} \mathrm{C}$ for 48 hours. Samples on PSB medium were cultured at $4^{\circ} \mathrm{C}$ for 21 days. Afterwards $0.5 \mathrm{ml}$ of each culture was transferred for $20 \mathrm{~s}$ into $4,5 \mathrm{ml}$ of $0.5 \% \mathrm{KOH}$ in $0.5 \%$ $\mathrm{NaCl}$. Then the loopful was streaked onto a CIN medium plate that includes cefsulodin, irgasan ${ }^{\mathrm{TM}}$ and novobiocin, and incubated at $28^{\circ} \mathrm{C}$ for 48 hours to revealed the $Y$. enterocolitica look-like colonies. After bacteriological examinations, forming a preliminary selection of potentially pathogenic strains, genomic DNA isolation was performed with the Genomic Mini Kit (A\&A Biotechnology, Gdynia, Poland) according to manufacturer;s instruction. Molecular examin- 
ations based on the amplification of ail, yst $A$ and yst $B$ genes fragments were done using HotStarTaq Plus DNA polymerase and HotStarTaq Plus Marker Mix Kit (Qiagen). The primers were synthesized in DNA Sequenceing Laboratory of the Biochemistry and Biophysics Institute of the Polish Academy of Sciences (Oligo, Warsaw. Poland). Sequences of the primers and multiplex PCR conditions were previously described by Bancerz-Kisiel et al. (2014).

\section{Results and Discussion}

From among 1656 rectal swabs cultured onto ITC/CIN and PSB/CIN media, colonies characteristic for $Y$. enterocolitica were detected in $538(32.5 \%)$ of the samples tested (Table 1). More than a half of positive results from ITC/CIN or PSB/CIN enrichment were isolated from wild boars (Fig. 1).

Our study is the first report showing the effectiveness of different methods of $Y$. enterocolitica isolation from so many free-living animals. According to Arrausi-Subiza at al. (2014), the concentration of pathogenic Yersinia in asymptomatic carriers is low and the standard PCR detection is difficult. The present results prove that culturing on PSB medium and subsequent molecular confirmation were the most effective methods for proper and detailed detection of $Y$. enterocolitica strains. The use of PCR in combination with PSB enrichment increases the number of pathogenic and non-pathogenic $Y$. enterocolitica strains isolated from asymptomatic animals with refer- ence to combination of PCR with ITC. It is crucial in monitoring of the environmental samples and could be used to increase the public health.

\section{References}

Arrausi-Subiza M, Ibabe JC, Atxaerandio R, Juste RA, Barrai M (2014) Evaluation of different enrichment methods for pathogenic Yersinia species detection by real time PCR. BMC Vet Res 10: 192.

Bancerz-Kisiel A, Szczerba-Turek A, Platt-Samoraj A, Socha P, Szweda W (2014) Bioserotypes and virulence markers of $Y$. enterocolitica strains isolated from roe deer (Capreolus capreolus) and red deer (Cervus elaphus). Pol J Vet Sci 17: 315-319.

Hanifian S, Khani S (2012) Prevalence of virulent Yersinia enterocolitica in bulk raw milk and retail cheese in northern-west of Iran. Int J Food Microbiol 155: 89-92.

Hussein HM, Fenwick SG, Lumsden JS (2001) A rapid and sensitive method for the detection of Yersinia enterocolitica strains from clinical samples. Lett Appl Microbiol 33: 445-449.

Lambertz ST, Granath K, Fredriksson-Ahomaa M, Johansson KE, Danielsson-Tham ML (2007) Evaluation of a combined culture and PCR method (NMKL-163A) for detection of presumptive pathogenic Yersinia enterocolitica in pork products. J Food Prot 70: 335-340.

Shayegani M, Stone WB, De Forge I, Root T, Parsons LM, Maupin $\mathrm{P}$ (1986) Yersinia enterocolitica and related species isolated from wildlife in New York State. Appl Environ Microbiol 52: 420-424.

Zadernowska A, Chajęcka-Wierzchowska W, Łaniewska-Trokenheim Ł (2014) Yersinia enterocolitica: A Dangerous, But Often Ignored, Foodborne Pathogen. Food Rew Int 30: 53-70. 